\title{
Connecting critical thinking, caring, and curiosity in nurse education: Exploring the beliefs and practices of nurse educators
}

\author{
Sandie G. Nadelson,, Louis S. Nadelson \\ University of Central Arkansas, Conway, AR, United States
}

Received: February 13, 2019

Accepted: April 3, 2019

Online Published: April 16, 2019

DOI: $10.5430 /$ jnep.v9n8p1

URL: https://doi.org/10.5430/jnep.v9n8p1

\begin{abstract}
A theoretical association exists between caring, critical thinking, and curiosity. We wanted to gain a deeper understanding about how the relationships translated to the perceptions and practices of nurse educators. We developed a survey of selected and free response items to gather a combination of quantitative and qualitative data related to nurse educators' perceptions and practices related to caring, critical thinking, and curiosity. We distributed an invitation to participate in our online survey research project through direct communication with a sample of nurse educators and posted the request to a handful of nurse educator social media sites and listservs. Forty-six nurse educators fully completed our survey. Findings include a mixture of positive perceptions about learning caring and curiosity, insights about the importance of caring and curiosity in nursing, and practices that included promoting critical thinking and curiosity among nurses. We follow the results with a discussion of implications for nurse education.
\end{abstract}

Key Words: Nursing, Student, Education, Caring, Curiosity, Critical thinking

\section{INTRODUCTION}

Identifying highly effective ways to teach critical thinking to nursing students has become the Holy Grail of nursing education. According to Huber and Kuncel, faculty members have experimented with using an array of strategies to improve students' abilities to use critical thinking in their clinical decision-making. ${ }^{[1]}$ The work of Huber et al. and results from a meta-analysis performed by Abrami and colleagues indicate that some educational methods are more success than others. ${ }^{[1,2]}$ Still, research indicates that nursing students' critical thinking skills and abilities tend to be under-developed upon graduation. ${ }^{[3]}$
The various skills and dispositions associated with critical thinking (CT) make teaching and learning CT challenging according to Abrami et al. ${ }^{[4]}$ To teach students to be effective critical thinkers, educators need to foster student development of strategies necessary to problem solve well. ${ }^{[4]}$ Thus, unless the factors of CT are taught (and learned), such as the associated dispositions and skills, the instruction is likely to have limited effectiveness. ${ }^{[1]}$ The need to attend to these factors when teaching students to be critical thinkers led us to wonder if nursing educators are teaching caring and curiosity to their students. Caring and curiosity are critical elements of critical thinking, and therefore, essential to being an effective critical thinker.

\footnotetext{
*Correspondence: Sandie G. Nadelson; Email: snadelson1@uca.edu; Address: School of Nursing, University of Central Arkansas, 201 Donaghey Ave, Conway, AR 72035, United States. 
In our research report, we review literature focusing on the relationships among caring, critical thinking, and curiosity; then we present findings from our mixed methods research focused on nursing educators' perceptions of critical thinking, caring, and curiosity. We conclude with our discussion, implications, limitations, and recommendations for future research.

\section{REVIEW OF LITERATURE}

2.1 Cognitive skills and dispositions of critical thinking In this review of literature, we begin with providing additional information on the skills and dispositions associated with critical thinking and then cover two specific dispositions that are the focus of this research project: caring and curiosity. As mentioned previously, Kaya, Senyuva and Bodur as well as others identified that critical thinking is a complex concept that includes both thinking skills and dispositions. ${ }^{[5]}$ Thus, there is justification for continuing to explore the relationships that skills and dispositions have with successful engagement in critical thinking.

The skills and abilities needed to be a successful critical thinker include an array of cognitive skills to effectively engage in, "analyzing, applying standards, discriminating, information seeking, logical reasoning, predicting, and transforming knowledge" according to Scheffer and Rubenfeld. ${ }^{[6]}$ In the context of nursing, the cognitive skills may be applied to information gathered through processes such as observation of patients, conversation with patients, vital signs, and medical testing data. We argue that associated cognitive skills are influenced by variations in the data, sources of information, and the application of the necessary knowledge, which impacts the capacity for nursing students and nurses to be effective critical thinkers.

For nursing students to be successful critical thinkers, they need to have the appropriate dispositions as a care-giver in conjunction with their compilation of cognitive skills. ${ }^{[7]}$ The term "dispositions" refers to personal characteristics that include both qualities of character and the mind that include mood and inclination. ${ }^{[8]}$ According to Peixoto and Peixoto ${ }^{[9]}$ a disposition is the, "attitudinal component that incorporates the affective domains, which are capable of influencing the logical, situational, purposive, and outcome-oriented thinking process." There are many dispositions necessary for people to be successful critical thinkers including aspects of being nurturing and caring, and being interested and curious, particularly of others. ${ }^{[10,11]}$ Findings from nursing research focused on teaching $\mathrm{CT}$ indicate that it is possible to teach students both the skills and dispositions needed to be better critical thinkers. ${ }^{[4]}$ Thus, there is justification for exploring nursing educators' perceptions of student caring and curios- ity learning and they are teaching their students to be caring and curious.

\subsection{Caring}

According to Beck and Lea, as well as Watson and Deary, defining and assessing caring is challenging due to the many facets and contexts that influence the construct. ${ }^{[12,13]}$ In nursing, the term "caring" typically refers to the process of providing support for the physical needs of a person or is a reference to displaying concern, compassion, and/or empathy for a person. ${ }^{[14]}$ Our interest lies with attending to the emotions or feelings of others and therefore, this aspect of caring was the focus of our research project. The lens of caring we choose to use is based on the conceptualization of caring developed by Watson and Woodward ${ }^{[14]}$ which focuses on the relationship of being with individuals in a relationship, which includes love, respect, and being present. Since being emotionally caring is fundamental to effective nursing, there is justification to continue to explore how educators are working to enhance levels of caring in students from multiple perspective.

Research indicates emotional caring levels are not fixed and can change over time. ${ }^{[15-18]}$ Some interventions seem to be more effective than others at enhancing caring. ${ }^{[17,19,20]}$ Change in caring levels can occur due to a variety of reasons such as developmental maturation, personal emotional reflection and development, and experiences that exposed individuals to situations in which they reflect deeply about the conditions and situations of others. ${ }^{[16,21]}$ Simulation has been found to be effective for teaching students to be more empathetic, which is a component of caring. ${ }^{[17]}$ This is particularly true when students participate in simulation as patients. ${ }^{[22]}$ However even though research does indicate that growth can occur through education, some people continue to question the possibility of individuals learning to be more caring. ${ }^{[18,23]}$

Given the complex interplay among the caring facets including compassion, empathy, respect, and attention, there is justification for examining how nurse educations are teaching caring. The research is especially important given the relationships among caring, curiosity and critical thinking. ${ }^{[24]}$

\subsection{Curiosity}

Litman and Pezzo state that curiosity can be defined in several ways, ${ }^{[25]}$ which is possibly one of the reasons that curiosity is typically not recognized and researched in nursing education. The complexity and ambiguity of the construct makes curiosity difficult to teach and measure. While curiosity may not typically be emphasized in nursing education programs, the construct continues to be integral to preparing 
nursing students to provide patients with safe and effective care. ${ }^{[26,27]}$ Thus, there is justification for efforts to explore how nursing educations define curiosity and their perceptions and practices related to student curiosity learning.

To explore curiosity among nursing educators, we adopted a framework in which curiosity is defined along three facets: epistemic, empathetic and, diversive. ${ }^{[25,28,29]}$ Epistemic curiosity is defined as engaging in inner quests for learning and knowledge. ${ }^{[30]}$ People with high levels of epistemic curiosity are drawn to reading and learning. Their quest for knowledge can lead them to develop a large mental database of facts and ideas. Epistemic curiosity is fundamental to lifelong learning and is certainly an attribute that we hope is acquired and embraced by all nursing graduates.

Diversive curiosity is defined as the desire to do something novel or different. ${ }^{[29]}$ The term "diversive" has a negative connotation. This type of curiosity can get people in trouble. For example, children often display a diversive curiosity. It is not unusual for young ones to light matches to see how things burn and can unintentionally set objects on fire. Certainly, a modicum of diversive curiosity is needed to add zest to life, but sometimes too much diversive curiosity is troublesome and leads to risky behavior. While we want to encourage students to develop some level of diversive curiosity, we also need to prepare them with the skills to reflect on the ramifications of their action if they are to act on their interests. The reflection prior to engaging in diversive curiosity actions is particularly critical if the conditions are related to patient care.

Empathetic curiosity, also called "social", "sociable" and "interpersonal", curiosity is defined as the desire to understand what people are experiencing including how they feel and what they are thinking. ${ }^{[31-34]}$ People who have high levels of empathetic curiosity have high desire to build network of colleagues and to show an emotional connection to others. Empathetic curiosity is particularly important in nursing as nurses need to be interested in people and find out about them in order to provide care directed towards their specific needs. For example, if nurses caring for mothers who had a stillbirth, did not ask about how the mothers are coping, they may not receive the emotional support needed to get through the experience. In addition to connecting with others, empathetic curiosity motivates individuals to do self-reflection and develop a deeper understanding of themselves. ${ }^{[25]}$ Engaging in self-reflection enhances nurses' abilities to provide safe and effective care. Thus, empathetic curiosity motivates nurses to learn more about their patients and to reflect deeper on their practice which likely leads to higher levels of quality care.
Dyche and Epstein ${ }^{[31]}$ recommend that health care educators not only focus on facts, methods and protocols but also develop students' curiosity. Undoubtedly, having empathetic, diversive, and epistemic curiosity is important to being an effective nurse. However, we argue that empathetic and epistemic curiosity are essential for caring, particularly in nursing. Further, we consider caring for others and being curious about the patient are essential for engaging in the critical thinking which is necessary to a highly effective nurse. Nursing research has touched on curiosity as an element of quality nursing care. For example, Wangensteen and colleageus ${ }^{[35]}$ studied the dispositions of newly graduated nurses and reported that being inquisitive is important to them being critical thinkers. Similarly, Scheffer and Rubenfield ${ }^{[6]}$ found that being inquisitive, which is part of epistemic curiosity, is an important component of critical thinking. The explicit measurement of the nurses' caring levels was not part of these studies. However, Scheffer and Rubenfield ${ }^{[6]}$ did indicate there seemed to be a relationship between the nurses' levels of critical thinking and caring.

As we have pursued our interest in fostering the effective teaching of critical thinking in nurse education, we have found a relation among caring, curiosity, and critical thinking. In our search of the literature we have not been able to find any empirical studies that investigated caring, curiosity and critical thinking as perceived and taught by nursing faculty. For this reason, we felt that studying what nursing educators believed and practiced could help lay a better foundation for future teaching and research. Thus, our study is exploratory and a step toward establishing a foundation for future investigations and development of effective interventions.

\section{Methods}

\subsection{Research question}

Our overarching research question was: What are nursing educators' perceptions of and practices in teaching their students to be caring and curious? To guide our research, we developed the following guiding research questions:

(1) What are nurse educators' perceptions of teaching and fostering curiosity and caring?

(2) What practices do nurse educators engage in to enhance their students' levels of curiosity?

(3) What is the relationship between the nurse educators' perceptions of and practices supporting and fostering caring and curiosity in others?

(4) How do nurse educators define curiosity and critical thinking?

(5) What do nurse educators perceive to be the attributes of a caring nurse, and does the attributes include being 
curious?

\subsection{Participants}

Our participants were the nurse educators that responded to our invitation to participate that we distributed via email and social media. We had 52 individuals link to our survey, and of those, 46 nursing educators completed at least $95 \%$ of the survey items. Our sample participants were on average 53.33 years old $(\mathrm{SD}=12.08)$ and had been working as nurse educators for an average of 12.39 years $(\mathrm{SD}=$ 9.88). Forty-two of the participants were from North America, three were from Africa, and one was from Europe. All but two of the participants worked in a nursing education program. Eighteen percent of the participants indicated they worked in pre-licensing programs, $27 \%$ worked in associated degree level RN preparation programs, $36 \%$ worked in bachelor degree level RN preparation programs, $5 \%$ worked with graduate students, and 14\% worked as educators in hospital settings. The majority $(78 \%)$ indicated that they use simulation as part of their nursing education endeavors.

\subsection{Measures}

Given the unique focus of our research we needed to develop a new survey to gather the data needed to answer our research questions. We developed the caring items of our survey based on the prior work of Nadelson and Nadelson ${ }^{[36]}$ and developed the curiosity items based on the prior work of Litman and Spielberger. ${ }^{[29]}$ We modified and edited some of the items to contextualize our survey for individuals working in nursing education. Our instrument included a brief demographics section, a subscale for teaching curiosity, a subscale for perceptions of curiosity and caring, and three qualitative items forced on knowledge and perceptions of caring and critical thinking.

Once we had created a full working version of our survey we established the validity by pilot testing the instrument with several nursing faculty members. Based on the feedback from the nursing faculty members we determined that our instrument had content and construct validity. In addition, based on the feedback from the nursing faculty members we made some minor adjustments to the instrument.

Our subscale for teaching curiosity included ten items that were focused on the elements of curiosity that faculty members emphasize to teach aspects of curiosity. The participants were asked to rate the level to which they encourage their students/nurses to think about contexts associated with curiosity. For example, we asked the participants, "How often do you encourage your students/nurses to think about: Being interested in how my contribution affects others." and "How often do you encourage your students/nurses to think about: Being eager to learn." The participants responded to the items using responses that ranged from "None at all" to "A great deal" using a 10-point sliding scale. The calculated Cronbach's Alpha for the subscale was .85 indicting an acceptable level of reliability.

In our subscale for perceptions of curiosity and caring included fourteen items. Participants responded to the question, "How much do YOU agree with these statements?" to statements such as, "Curiosity is an essential quality that all nurses must have" and "Simulations can help students learn to be more curious" and "I believe you can teach people to be more caring." The participants responded to the items using responses that ranged from "Strongly disagree" to "Strongly agree" using a 10-point sliding scale. The calculated Cronbach's Alpha for the subscale was .81 indicting an acceptable level of reliability.

We designed the three qualitative items in our survey to gather participant perceptions or thoughts about curiosity, critical thinking and caring. Our questions were "What is curiosity?" "How do you define "critical thinking'?" and "What are the key components of a caring nurse?" The participants were provided unlimited space to answer the items, but we anticipated brief responses and, therefore, we provided a single-line box (which expands with the entered text) for the responses.

\subsection{Data collection}

All data collection took place online using a web-based survey tool. To recruit participants, we used a combination of email and social media postings. We relied on email to send invitations to nursing faculty members that we had access to and were familiar with us are researchers. We also posted the invitation to participate on social media sites that focused on nursing education and were likely to be followed by nurse educators. We posted on sites found through both Facebook and Twitter. We collected data until there were five consecutive days with no hits on our web-based survey.

\section{ReSUlts}

\subsection{Perceptions of teaching caring and curiosity}

Our first guiding research question asked: What are nurse educators' perceptions of teaching and fostering curiosity? To answer this question, we examined the responses to our items related to teaching curiosity and the perceptions of learning curiosity and caring. Our analysis of the item asking the participants if they believed that people can to taught to be curious revealed a mean of $7.61(\mathrm{SD}=1.98)$. A higher number represents greater agreement. The average indicates that the participants, as a whole, tended to somewhat agree to agree that curiosity can be taught but were not totally com- 
mitted to the concept. Similarly, when asked about teaching people to be caring the average of $6.98(\mathrm{SD}=2.40)$ suggests that the participants somewhat agree with the concept.

In contrast, the participants also tended to somewhat agree to agree that curiosity is something people are born with and does not change $(\mathrm{M}=7.65, \mathrm{SD}=1.65)$. Also, the participants agreed that caring levels of individuals are constant throughout their life $(M=7.82, S D=1.70)$. Thus, it appears that, as a whole, the participants seem to agree that people can learn to be caring and curious but also seem to hold the perception that individual levels of caring and curiosity are fixed.

The participants responded with strongly agree $(M=9.04$, $\mathrm{SD}=1.91)$ to the idea that preparing professionals that are curious is important to them. The participants also agreedstrongly agreed that they often think about how they can encourage their students to be more curious ( $\mathrm{M}=8.67$, SD $=1.33$ ). However, they were more ambivalent to the notion that they plan activities that help their students to become more caring $(\mathrm{M}=6.65, \mathrm{SD}=2.50)$. The participants were also more ambivalent to the notion that simulation could be a useful approach to teaching caring $(\mathrm{M}=6.30, \mathrm{SD}=2.66)$. Thus, the participants seem to be more likely to emphasize the development of curiosity than the development of caring in their students.

\subsection{Practices to support development of curiosity}

Our second guiding research question asked: What practices do nurse educators engage in to enhance their students' levels of curiosity? To answer this question, we examined the responses to the items in our teaching curiosity subscale. Our analysis revealed that the educators tended to encourage their students to be eager to learn and engage in information until it is understood to a great extent (see Table 1). In contrast, the educators were less likely to encourage their students to think about being interested in how their contributions affect others and to critically examine existing theories.

Table 1. Frequency of encouraging students/nurses to be curious (10-Point Scale - Never to Constantly)

\begin{tabular}{lll}
\hline How often do you encourage your students/nurses to think about & M & SD \\
\hline Being eager to learn. & 8.98 & 1.27 \\
Engaging in seeking information until I understand complex issues. & 8.33 & 1.47 \\
Continuing to think about problems until a solution is found. & 8.00 & 1.57 \\
Confronted complex problems by seeking new solutions. & 7.83 & 1.79 \\
Trying to improve work processes by making innovative suggestions. & 7.80 & 2.31 \\
Enjoying pondering and thinking about solutions to complex problems. & 7.50 & 1.93 \\
Being interested in the underlying theory of practical problems. & 7.39 & 2.33 \\
Enjoying developing new strategies for accomplishing work. & 7.04 & 2.10 \\
Being interested in how my contribution affects others. & 6.48 & 2.17 \\
Critically challenging existing theories. & 5.87 & 2.57 \\
\hline
\end{tabular}

Our results suggest that the educators are selective about the focus of their encouragement they provide to their students that may foster the development of curiosity.

\subsection{Relationship between perceptions and practices}

Our third guiding research question asked: What is the relationship between the nurse educators' perceptions of and practices supporting and fostering caring and curiosity in others? To answer this question, we calculated the correlations among the perception items which included five questions and teaching items that included 11 questions.

Our analysis revealed a number of significant and nonsignificant correlations. We found perceptions that simulations can help people be more curious to be related to teaching students to seek new solutions $(r=.36, p<.05)$, with teaching students to think about improving work pro-

Published by Sciedu Press cesses $(r=.54, p<.01)$, and with planning activities that they perceive can help students to become more caring $(r=.32, p$ $<.05)$. Data indicate the participants' level of agreement with the possibility of teaching people to be more curious to be correlated with teaching students to ponder solutions $(r=.41$, $p<.01)$, with teaching students to be eager to learn $(r=.50$, $p<.01$ ), with teaching students to ponder problem until they find solutions $(r=.37, p<.05)$, with teaching students to seek information until they understand $(r=.49, p<.01)$, and with planning activities that they perceive can help students to become more caring $(r=.30, p<.05)$.

We found the participants' level of agreement with the possibility of teaching people to be more caring to be correlated with teaching students that their contribution to situations can affect others $(r=.31, p<.05)$, with teaching students to seek 
new solutions $(r=.34, p<.05)$, with teaching students to ponder solutions $(r=.33, p<.05)$, with teaching students to critically challenge theories $(r=.45, p<.01)$, with teaching students to think about improving work processes $(r=.42, p$ $<.01$ ), with planning activities to teach students to be more creative $(r=.48, p<.01)$, and with planning activities that they perceive can help students to become more caring ( $r=$ $.69, p<.01)$.

The data supports the conclusion that the participants' level of perception that curiosity is essential for nurses to only be correlated with teaching students to ponder problem until they find solutions $(r=.33, p<.05)$. Similarly, we found the participants' level of perception that preparing professionals to be curious to only be correlated with teaching students to be eager to learn $(r=.50, p<.01)$.

\subsection{Defining curiosity and critical thinking}

Our fourth guiding research question asked: How do nurse educators define curiosity and critical thinking? To answer this question, we analyzed the qualitative responses to our items asking the participants to share how they define curiosity and critical thinking. To analyze the data, we coded the responses using content analysis as prescribed by Miles, Huberman and Saldana. ${ }^{[37]}$

Our analysis of the responses to our curiosity item revealed "know more" or "learn more" or "understand more" "desire to find out what..." were the most frequent occurring followed by "seeking information" or "seeking solutions." Several of the participants indicated that curiosity involves "wondering" such as in this response, "Persistent wondering beyond what is currently happening." Many of the participants indicated that curiosity is internally driven as reflects in these responses, "self-directed inquiry" and "eagerness to know" and "seeking answers". One participant shared, "... some people are curious about many things and some are curious about very little" indicating that the participants perceive that curiosity is internal to people and involves self-motivated learning and gaining deeper knowledge or understanding. We found a mixture of responses indicating that curiosity can be passive such as in this statement, "a desire to know more" while others indicated that curiosity involves action, such as in this statement "Being curious is an action activity. It is done through exploration." Only two participants indicated curiosity includes learning about "who" such as in this response, "Curiosity is the desire to find out who, what, when, and where." Thus, in general it appears that the participants' responses suggest that they do not particularly perceive curiosity as learning about the needs, challenges, or struggles of a person or other people. We present the percentage of answers by content in Figure 1.

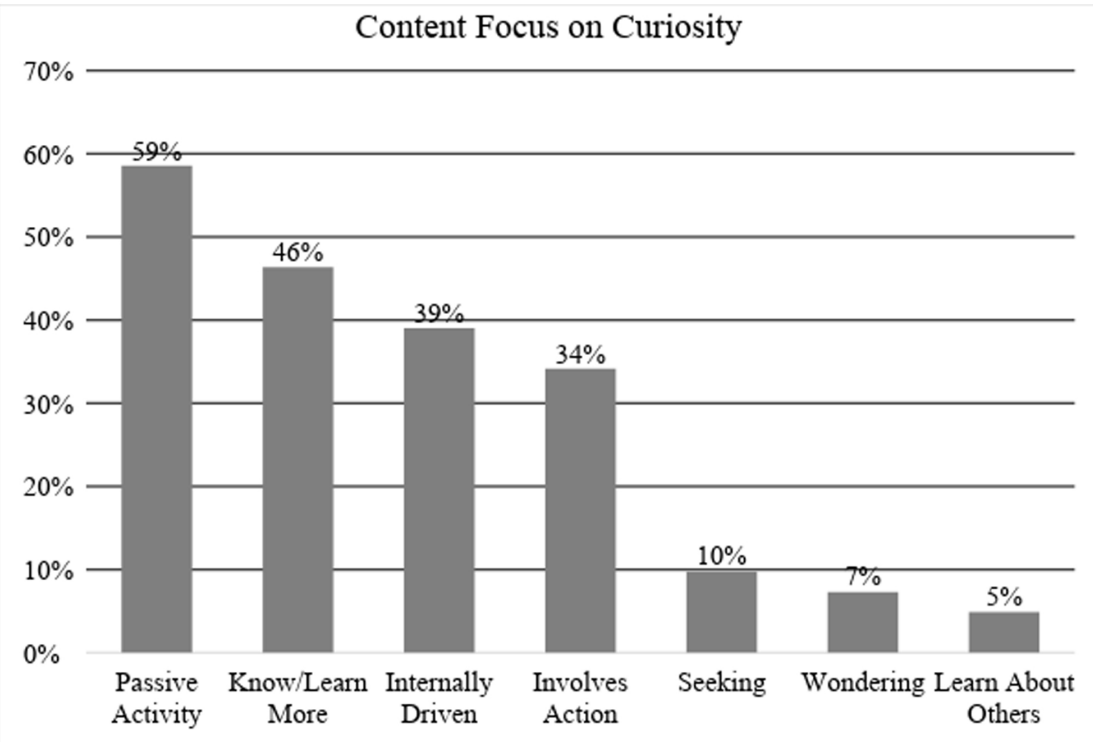

Figure 1. Percentage of content responses to defining curiosity

Our analysis of the responses to our item requesting the participants to define critical thinking revealed a wide range of perspectives and definitions. Several of the participants indicated that critical thinking is defined as application of knowledge as in this response, "Using knowledge, skills and experience to solve problems" while others defined critical thinking as a process of assessing situations such as in this response, "think 360 degrees on pros and cons." Many of the participants indicated that critical thinking is defined by finding solutions or solving problems which is reflected in 
these responses, "Work out a problem in your mind" and "The ability to address a situation and prioritize steps to a solution." Some of the participants defined critical thinking in terms of understanding situations such as in this response, "Understanding the information before me and anticipating what else might happen, also looking at consequences of my actions." A few of the participants defined critical thinking in terms of thinking without necessarily taking action as reflected in this response, "identifying strengths and weaknesses, analysis and synthesis." A small number of the participants did link critical thinking to caring for others such as in these responses, "Being able to look at issues through various ways to care for pts." and "Reflective practice is a form of critical thinking" and "First, understanding what is important (critical) in providing care for others, in terms of their safety and their values, then acting on that knowledge to determine appropriate interventions." Thus, our data indicate that the participants tended to perceive critical thinking in terms of application of the result of the critical thinking by developing solutions and preparing for or actually taking action. See Figure 2 for the distribution of the content responses.

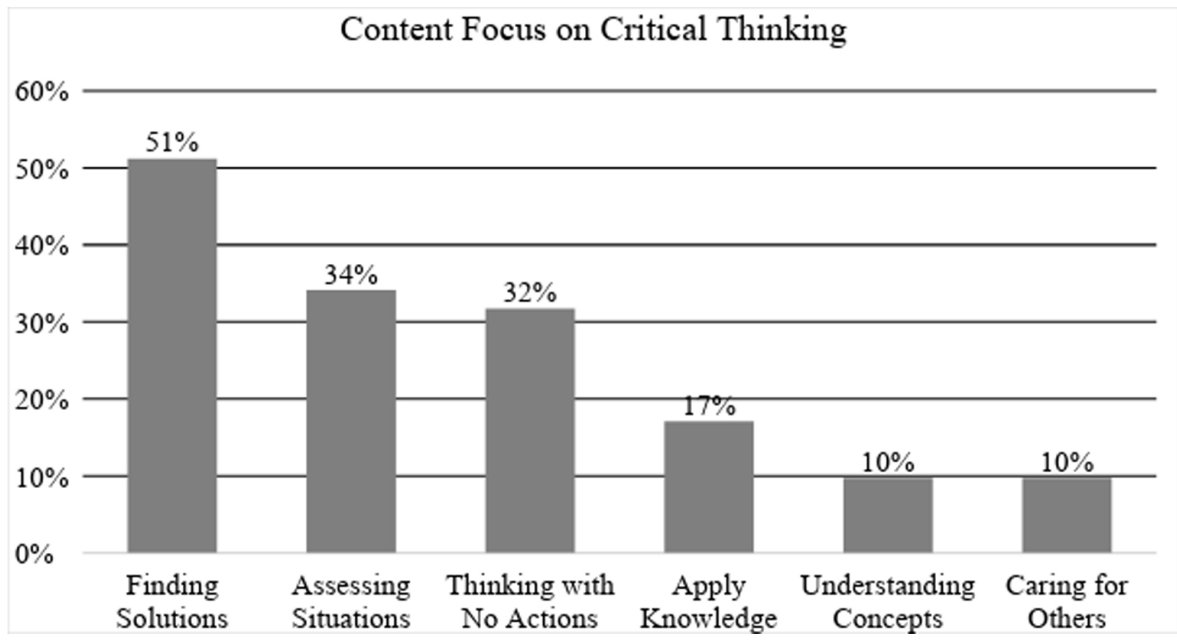

Figure 2. Percentage of coded responses to defining critical thinking

\subsection{Attributes of caring nurses}

Our fifth guiding research question asked: What do nurse educators perceive to be the attributes of a caring nurse, and do the attributes include being curious? To answer this question, we analyzed the qualitative responses to our item asking the participants to share what they think are the attributes of a caring nurse. To analyze the data, we again coded the responses using content analysis. ${ }^{[37]}$

Our analysis of the responses indicates that the majority of the participants consider "compassion" and "empathy" and being "selfless" to be key elements of a caring nurse as reflect in this passage, "Empathy, compassion and putting someone else's needs as a priority." Several of the participants indicated a caring nurse is "kind" or "respectful" as reflected in this response, "Compassionate, respectful, intelligent, knowledgeable, ethical, teaching/educating, honest, kind." Multiple participants indicated a caring nurse "takes time with patients" and are "good communicators" as reflected in these responses, "taking time with patient care and not rushing to complete tasks" and "Good communication and listening with your heart." A number of participants also indicated that "liking people" or being a "people person" is important to being a caring nurse as reflected in this response, "liking the people you work - the patients, other healthcare providers." Several of the participants included "knowledgeable" or "learner" or "curious" in their responses, such as this participant's response, "Compassion, advocate, listener, and life-long learner." Similarly, these participants responses, "authentic presence", "discovering what matters most", "holistic approach," and "Energy, interest, selflessness, and kindness" reflect consideration of a caring nurse involving engagement in both critical thinking and curiosity to be interested and to learn what matters most. A handful of participants indicated they considered "competency" as a key component of a caring nurse as reflected in this response, "focusing on caregiving and being competent in providing care to the patient and their family." Considered collectively, it is apparent that the participants perceive multiple attributes are key to caring nurses which includes associations with curiosity and critical thinking. See Figure 3 for the distribution of the content responses. 


\section{Content Focus for Caring Nurses}

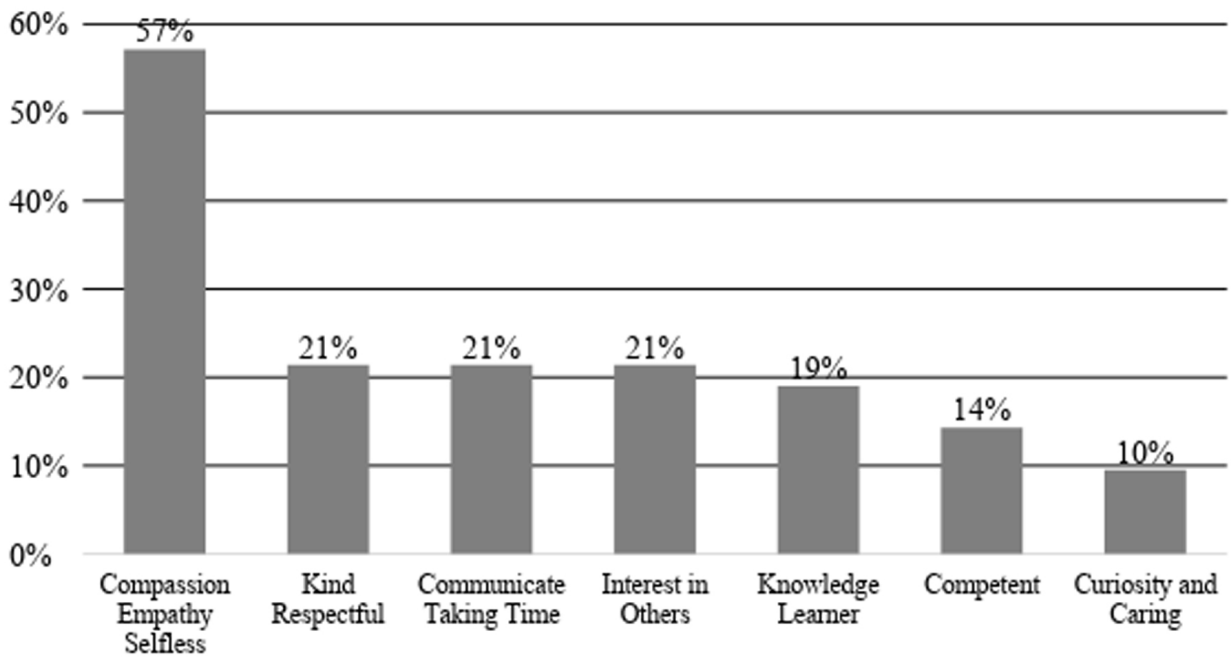

Figure 3. Percentage of coded responses to key components of a caring nurse

\section{DisCUSSION AND IMPLICATIONS}

The premise for our investigation was curiosity and critical thinking are essential attributes of a caring nurse. To test our premise, we designed a study based on a synthesis of literature from a collection of scholars such as Profetto$\mathrm{McGrath}^{[38]}$ who maintains that curiosity is fundamental to nurses' engagement in critical thinking, Thayer-Bacon ${ }^{[24]}$ who argues that caring is necessary for effective engagement in critical thinking, and Baumgarten ${ }^{[26]}$ who contends that one cannot be caring without being curious. Given the association between caring, curiosity, and critical thinking and the essential integration of the constructs in the work of nurses, we determined it was necessary to assess the perception, knowledge and teaching of the constructs among nursing educators. We believe our findings are consistent with those of past research and theorists. They do add to the understanding of these complex concepts and relationships. We interpret our finding of nurse educators' tentative acceptance of the ability to teach caring and curiosity as being reflective of their rather short-term interactions with their students and the potentially long-term development of dispositions. We speculate that the participants were considering the development in terms of their courses or professional development and not in terms of program or a long-term intervention. No literature could be found to support this supposition. However, it does match our understanding of health care educator's thoughts and behaviors.

The finding that the participants perceived caring and curious nurses to be important and indicated that they thought about ways to make their students more curious, when they were tentative about whether their students could be taught to be more curious, were a bit confusing to us. Again, we wonder if the nurse educators were considering long-term changes when considering learning about caring and curiosity while also feeling that they have some responsibility in helping their students develop their dispositions. Once again, literature about this conclusion could not be found. Exploring more deeply the perceptions of teaching and learning caring and curiosity among nurse educators in likely to be a fruitful direction for future research.

In our exploration of the nurse educators' perceptions and definitions of curiosity and critical thinking using qualitative data, caring for others was among the least communicated facets of these constructs even though according to the work of Watson and Woodward this is a key role of nurses. ${ }^{[14]} \mathrm{We}$ were rather surprised that nurse educators would not consider the relationship to caring with a larger frequency. We speculate that many nurse educators consider curiosity and critical thinking from a treatment protocol perspective, which typically does not include emphasis on being empathetic or compassionate. Shifting the conversation to a more holistic perspective, caring as related to curiosity and informing critical thinking may lead to different perspectives about being empathetic and compassionate that may result in greater effectiveness in nursing practice. The current nursing literature on these topics does not support or refute this notion. Examining the influence of nurse educators placing greater emphasis on empathy and compassion and the association to curiosity and better critical thinking is likely to be a very important line of research. 


\section{Limitations}

As with all research, there are limitations to the study. The sample size was small and could reflect a limited representation of faculty members perceptions related to caring, $\mathrm{cu}-$ riosity, and critical thinking. Since we drew our sample from online sources, there is likely some variety in opinions and perspectives representative of a variety of viewpoints. Studies focusing on specific nursing education populations (e.g. pre-graduate, graduate, and post graduate) may provide additional insight into nursing educators' perceptions of teaching caring and curiosity.

Another limitation is the broad concepts that we have made the focus of our research may not have been fully incorporated into our survey. Thus, faculty members' personal definitions of caring, curiosity, and critical thinking may vary widely which would influence our results. Because of these variations, we maintain our study is exploratory and, therefore, ground breaking with the need for additional methods, tools and data to provide sufficient evidence to create a comprehensive perspective of nurse educators. Again, related research is needed and could build upon our study, and is critical for corroborating our finding.

\section{Conclusion}

Our research study focused on nursing educators' perceptions and practices related to caring and curiosity. In addition, we examined the potential for the association to critical thinking, which has curiosity and caring as dispositions. Our findings indicate that these concepts are important in nursing education. The connection between caring and curiosity with critical thinking were not clearly identifiable in data. As a result, we suggest further research be conducted on the links between caring, curiosity, and critical thinking.

Another future step is to examine how caring and curiosity can be enhanced in nursing students and practicing nurses. We believe that building additional methods for teaching these important constructs is critical to the advancement of high-quality health care. We also recommend that additional research is needed that identify highly effective practices for preparing nurses to express high levels of both caring and curiosity in conjunction with positively productive critical thinking.

\section{Conflicts of InTEREST Disclosure}

The authors declare that there is no conflict of interest.

\section{REFERENCES}

[1] Huber CR, Kuncel NR. Does college teach critical thinking? A metaanalysis. Review of Educational Research. 2016; 86(2): 431-468. https://doi.org/10.3102/0034654315605917

[2] Abrami PC, Bernard RM, Borokhovski E, et al. Strategies for teaching students to think critically: A meta-analysis. Review of Educational Research. 2015; 85(2): 275-314. https://doi.org/10.3 102/0034654314551063

[3] Gezer N, Yildirim B, Özaydin E. Factors in the critical thinking disposition and skills of intensive care nurses. Journal of Nursing Care. 2017; 6(390): 2167-1168

[4] Abrami PC, Bernard RM, Borokhovski E, et al. Instructional interventions affecting critical thinking skills and dispositions: A stage 1 meta-analysis. Review of Educational Research. 2008; 78(4): 11021134. https://doi.org/10.3102/0034654308326084

[5] Kaya H, Şenyuva E, Bodur G. Developing critical thinking disposition and emotional intelligence of nursing students: a longitudinal research. Nurse Education Today. 2017; 48: 72-77. PMid:27721088 https://doi.org/10.1016/j.nedt.2016.09.011

[6] Scheffer BK, Rubenfeld MG. A consensus statement on critical thinking in nursing. Journal of Nursing Education. 2000; 39: 352-359. https://doi.org/10.3928/0148-4834-20001101-06

[7] Facione PA. The disposition toward critical thinking: Its character, measurement, and relationship to critical thinking skill. Informal Logic. 2000; 20(1).

[8] Merriam-Webster [Internet] Disposition. 11th ed. 2019. [cited 2019 Feb 13]. Available from: https://www.merriam-webster.com /dictionary/disposition

Published by Sciedu Press
[9] Peixoto TAS, Peixoto NMS. Critical thinking of nursing students in clinical teaching: an integrative review. Revista de Enfermagem Referência. 2017; 4(13): 125-138.

[10] Facione P. Critical thinking: A statement of expert consensus for purposes of educational assessment and instruction. Millbrae: California Academic Press; 1990.

[11] Facione N, Facione P, Sanchez C. Critical thinking disposition as a measure of competent clinical judgment: The development of the California Critical Thinking Disposition Inventory. The Journal of Nursing Education. 1994; 33(8): 345-350. PMid:7799093

[12] Beck CT. Caring within nursing education: A metasynthesis. Journal of Nursing Education. 2001; 40(3): 101-109. PMid:11302537

[13] Lea A, Watson R, Deary IJ. Caring in nursing: a multivariate analysis. Journal of Advanced Nursing. 1998; 28(3): 662-671. https://doi.org/10.1046/j.1365-2648.1998.00799.x

[14] Watson J, Woodward TK. Jean Watson's theory of human caring. Nursing Theories and Nursing Practice. 2010; 3: 351-369.

[15] Blum CA, Hickman C, Parcells DA, et al. Teaching caring nursing to RN-BSN students using simulation technology. International Journal for Human Caring. 2010; 14(2): 41-50.

[16] Nadelson SG, Zigmond T, Nadelson LS, et al. Fostering caring in undergraduate nursing students: An integrative review. Journal of Nursing Education and Practice. 2016; 6(11): 7-14. https : //doi.org/10.5430/jnep.v6n11p7

[17] Persaud S, Thornton M. Developing caring behaviors in undergraduate nursing students through simulation. International Journal for Human Caring. 2018; 22(2): 26-33. https ://doi .org/10.20467 $/ 1091-5710.22 .2 .26$ 
[18] Richardson C, Percy M, Hughes J. Nursing therapeutics: teaching student nurses care, compassion and empathy. Nurse Education Today. 2015; 35(5): e1-e5. https://doi.org/10.1016/j.nedt.2 015.01 .016

[19] Horsburgh D, Ross J. Care and compassion: the experiences of newly qualified staff nurses. Journal of Clinical Nursing. 2013; 22(78): 1124-1132. PMid:23480502 https://doi.org/10.1111/jo cn. 12141

[20] Wear D, Zarconi J. Can compassion be taught? Let's ask our students. Journal of General Internal Medicine. 2008; 23(7): 948-953. PMid:18612722 https ://doi.org/10.1007/s11606-007-050 1-0

[21] Noddings N. Caring: A relational approach to ethics and moral education. Univ of California Press; 2013.

[22] Bearman M, Palermo C, Allen LM, et al. Learning empathy through simulation: a systematic literature review. Simulation in Healthcare. 2015; 10(5): 308-319. PMid:26426561 https://doi.org/10.1 097/SIH. 0000000000000113

[23] Paley J. Social psychology and the compassion deficit. Nurse Education Today. 2013; 33(12): 1451. PMid:23786868 https://doi.or g/10.1016/j.nedt.2013.05.011

[24] Thayer-Bacon BJ. Caring and its relationship to critical thinking. Educational Theory. 1993; 43(3): 323-340. https ://doi .org/10 $.1111 / j .1741-5446.1993 .00323 . x$

[25] Litman JA, Pezzo MV. Dimensionality of interpersonal curiosity. Personality and Individual Differences. 2007; 43(6): 1448-1459. https://doi.org/10.1016/j.paid.2007.04.021

[26] Baumgarten E. Curiosity as a moral virtue. International Journal of Applied Philosophy. 2011; 15(2): 169-184. https ://doi.org/10 .5840/ijap200115215

[27] Profetto-McGrath J. Critical thinking and evidence-based practice. Journal of Professional Nursing. 2005; 21(6): 364-371. PMid:16311232 https://doi.org/10.1016/j.profnurs. 200 5.10 .002

[28] Renner B. Curiosity about people: The development of a social curiosity measure in adults. Journal of Personality Assessment. 2006;
87(3): 305-316. PMid:17134338 https ://doi.org/10.1207/s1 5327752jpa8703_11

[29] Litman JA, Spielberger CD. Measuring epistemic curiosity and its diversive and specific components. Journal of Personality Assessment. 2003; 80(1): 75-86. PMid:12584070 https ://doi .org/10.120 7/S15327752JPA8001_16

[30] Berlyne DE. A theory of human curiosity. British Journal of Psychology General Section. 1954; 45(3): 180-191. https://doi.org/10 .1111/j.2044-8295.1954.tb01243.x

[31] Dyche L, Epstein RM. Curiosity and medical education. Medical Education. 2011; 45(7): 663-668. PMid:21649698 https://doi. org/10.1111/j.1365-2923.2011.03944.x

[32] Litman JA, Robinson OC, Demetre JD. Intrapersonal curiosity: Inquisitiveness about the inner self. Self and Identity. 2017; 16(2): 231250. https://doi.org/10.1080/15298868.2016.1255250

[33] McEvoy P, Baker D, Plant R, et al. Empathic curiosity: Resolving goal conflicts that generate emotional distress. Journal of Psychiatric and Mental Health Nursing. 2013; 20(3): 273-278. PMid:22632763 https://doi.org/10.1111/j.1365-2850.2012.01926.x

[34] Phillips R. Curious about others: Relational and empathetic curiosity for diverse societies. New Formations. 2016; 88(88): 123-142. https://doi.org/10.3898/NEWF.88.02.2016

[35] Wangensteen S, Johansson IS, Björkström ME, et al. Critical thinking dispositions among newly graduated nurses. Journal of Advanced Nursing. 2010; 66(10): 2170-2181. PMid:20384637 https : //doi.org/10.1111/j.1365-2648.2010.05282. $\mathrm{x}$

[36] Authors. Students as carers across three disciplines: Quantifying student caring in higher education. The Researcher. 2010; 23(1): 59-73.

[37] Miles MB, Huberman AM, Saldana J. Qualitative data analysis. Sage; 2014.

[38] Profetto-McGrath J. Critical thinking and evidence-based practice. Journal of Professional Nursing. 2005; 21(6): 364-371. PMid:16311232 https://doi.org/10.1016/j.profnurs . 200 5.10 .002 